\title{
Chinese medicines in the treatment of experimental diabetic nephropathy
}

\author{
Jing-Yi Liu' ${ }^{1}$ Xiao-Xin Chen ${ }^{1}$, Sydney Chi-Wai Tang ${ }^{2 *}$, Stephen Cho-Wing Sze' ${ }^{1}$ Yi-Bin Feng ${ }^{1}$, Kai-Fai Lee ${ }^{3}$ \\ and Kalin Yan-Bo Zhang ${ }^{1 *}$
}

\begin{abstract}
Diabetic nephropathy (DN) is a severe micro vascular complication accompanying diabetes mellitus that affects millions of people worldwide. End-stage renal disease occurs in nearly half of all DN patients, resulting in large medical costs and lost productivity. The course of DN progression is complicated, and effective and safe therapeutic strategies are desired. While the complex nature of DN renders medicines with a single therapeutic target less efficacious, Chinese medicine, with its holistic view targeting the whole system of the patient, has exhibited efficacy for DN management. This review aims to describe the experimental evidence for Chinese medicines in DN management, with an emphasis on the underlying mechanisms, and to discuss the combined use of herbs and drugs in DN treatment.
\end{abstract}

\section{Background}

Diabetic nephropathy (DN) is a serious micro vascular complication in patients with diabetes mellitus (DM), affecting approximately $40 \%$ of patients with type 1 or type $2 \mathrm{DM}[1,2]$. It is the predominant cause of chronic kidney disease and renal failure, and is closely associated with many micro vascular diseases, leading to financial and medicinal burdens [3]. Continued hyperglycemia associated with DM is the major cause of kidney dysfunction with metabolic and hemodynamic disorders arising from oxidative stress and inflammation [4].

During DN progression, progressive alterations developfrom hyperfiltration through micro albuminuria to macro albuminuria, and finally to renal failure [5]. Renal structural changes are found in the nephrons, especially in the primary part of the glomerulus, including podocyte loss, glomerular basement membrane (GBM) thickening, endothelial cell dysfunction, and mesangial extracellular matrix (ECM) expansion, resulting in

\footnotetext{
*Correspondence: scwtang@hku.hk; ybzhang@hku.hk

1 School of Chinese Medicine, Li Ka Shing Faculty of Medicine, The University of Hong Kong, 10 Sassoon Road, Hong Kong, People's Republic of China

${ }^{2}$ Department of Medicine, Li Ka Shing Faculty of Medicine, The University of Hong Kong, 10 Sassoon Road, Hong Kong, People's Republic of China
} Full list of author information is available at the end of the article protein leakage into the urine [6]. Pulmonary dysfunction [7], hyperlipidemia and non-alcoholic fatty liver disease [8], cardiovascular disease [9], and even heart failure [10] have been reported to be positively associated with DN progression. Therefore, synergistic therapies targeting multiple mediators of $\mathrm{DN}$ are required for effective therapeutic strategies [4].

The experimental models used for studying Chinese medicines (CMs) in DN treatment are diverse. For in vivo studies, different doses of streptozotocin (STZ) are administered to mimic type 1 or type 2 DM. Examples of the CMs that have been investigated are Glycyrrhizauralensis (gan-cao), Carumcarvi (zang-hui-xiang), Allium sativum (da-suan), and Mesonaprocumbens (xian-cao) [11-14]. In addition, alloxan (ALX)-induced mice, $\mathrm{db} / \mathrm{db}$ mice, KK-Ay mice, and Otsuka Long-Evans Tokushima Fatty (OLETF) rats have been reported for investigation of CMs in DN treatment [15-18]. Meanwhile, glomerular endothelial cells, mouse podocyte cells, renal proximal epithelial cells, murine hepatocytes, mouse mesangial cells, and human mesangial cells are used as in vitro models for anti-DN mechanism studies [19-27]. By applying these models, the majority of studies have reported that CMs such as Acacia nilotica pods (jin-he-huan) [28], Artemisia campestris (huangye-hao) [29], Paeonialactiflora (shao-yao) [30], and 
Schisandra chinensis (wu-wei-zi) [21,31] exhibited beneficial effects on all stages of experimental DN and may protect multiple organs. Grapevine leaf (Vitis labrusca) extract was reported to exert hepatoprotective, cardioprotective, and renoprotective effects [32]. Moreover, CM preparations such as Fufang Xueshuantong Capsule (fu-fang-xue-shuan-tong-jiao-nang), Zhengqing Recipe (zheng-qing-fang), and Danggui Buxue Tang demonstrated benefits for DN patients [33-35]. Representative $\mathrm{CMs}$ for the treatment of $\mathrm{DN}$ at different stages of disease progression and their underlying mechanisms are shown in Fig. 1.

This article aims to review the experimental evidence for the effectiveness of CMs in DN management, with emphasis on their underlying mechanisms, and to discuss the combined use of CM herbs and chemical drugs in DN treatment.

\section{Search strategy and selection criteria}

We searched for the terms "traditional Chinese medicine", "holistic therapy", and "traditional Chinese medicine prescriptions (or formula)" in combination with "diabetic nephropathy" and "diabetes" in PubMed, Google Scholar, and Web of Science between 1990 and 2014. Manual searches of in-text references from the selected articles were further performed. Studies were included if in vivo models were used to investigate the nephroprotective effects and mechanisms of CMs. Unpublished reports, Letters to the Editor, and the studies that only used in vitro models or did not provide information about the duration of animal studies were excluded.

\section{CMs in experimental DN management \\ CMs intervention in the early stage of experimental DN}

The potential signaling pathways involved in DN pathogenesis regulated by CMs are shown in Fig. 2. The early stage of DN is characterized by hyperfunction and hypertrophy arising from oxidative stress and inflammation $[3,36,37]$. Under chronic hyperglycemia, the extracellular glucose forms advanced glycation end-products (AGEs). Activation of receptor of advanced glycation end-products (RAGE) on the plasma membrane has been proposed to contribute predominantly to the overproduction of reactive oxidative species (ROS) [38].

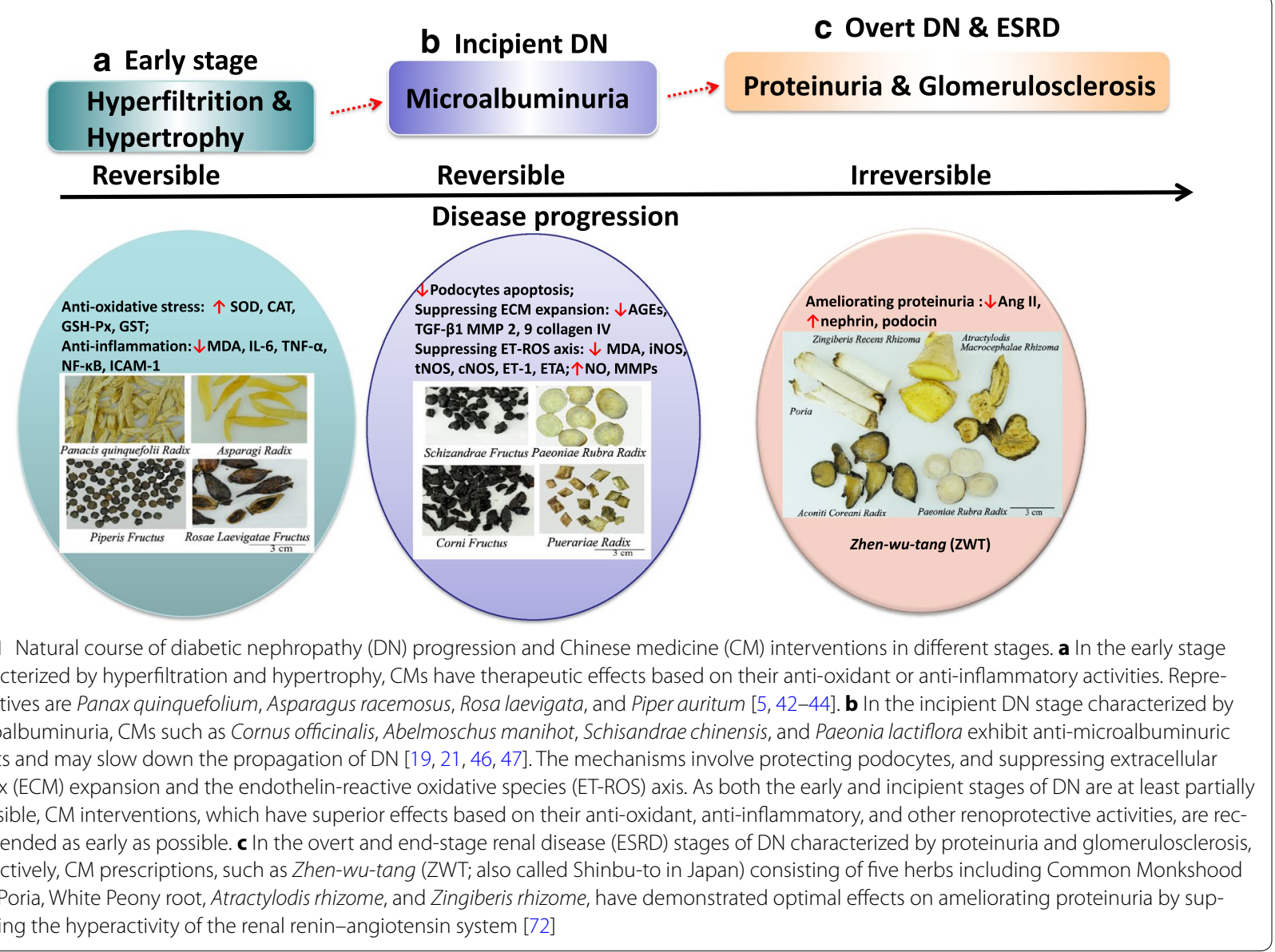




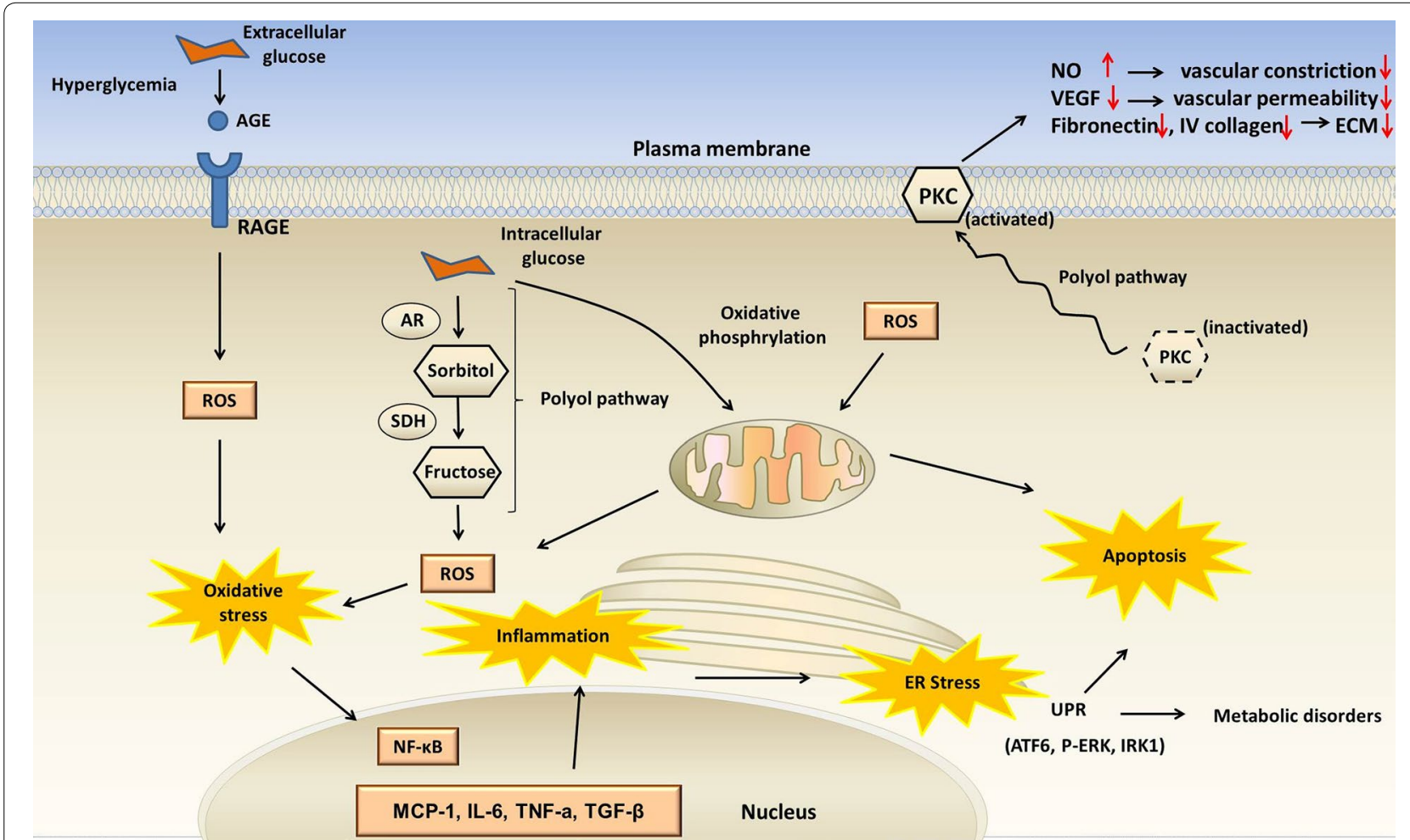

Fig. 2 Potential signaling pathways involved in diabetic nephropathy (DN) pathogenesis. Activation of receptor of advanced glycation endproducts (RAGE) by advanced glycation end-products (AGEs) results in reactive oxidative species (ROS) overproduction, leading to oxidative stress. Meanwhile, the polyol pathway activated by intracellular glucose further aggravates the oxidative stress. Activation of protein kinase C (PKC) via the polyol pathway is another major source of ROS production. Mitochondrial damage also contributes to ROS production. ROS overproduction and impaired anti-oxidant response cause oxidative stress, which activates nuclear factor (NF)-kB and upregulates monocyte chemoattractant protein (MCP)-1, interleukin (IL)-6, tumor necrosis factor (TNF)-a, and transforming growth factor (TGF)- $\beta$. Thereafter, the inflammation induces endoplasmic reticulum (ER) stress via unfolded protein response pathways, resulting in metabolic disorders and apoptosis

Meanwhile, the polyol pathway of glucose metabolism activated by the intracellular glucose further aggravates the oxidative stress. Other major sources of excess ROS were reported to be enhanced protein kinase $\mathrm{C}$ (PKC) activity caused by activation of the polyol pathway [39] and mitochondrial ROS production in response to mitochondrial damage. As a consequence, nuclear factor (NF) $-\kappa B$ becomes activated, followed by stimulation of pro-inflammatory cytokines (e.g., interleukin [IL]6), chemokines (e.g., monocyte chemoattractant protein $[\mathrm{MCP}]-1$ ), adhesion molecules (e.g., intercellular adhesion molecule 1 [ICAM1], vascular cell adhesion protein 1 [VCAM1]), and nuclear receptors (e.g., peroxisome proliferator-activated receptor [PPARs]) [40]. Thereafter, the inflammation induces endoplasmic reticulum (ER) stress via unfolded protein response pathways, resulting in metabolic disorders and apoptosis. Besides, subsequent macrophage infiltration into renal tissues leads to prolonged micro inflammation, thus aggravating the progression of $\mathrm{DN}$. Numerous $\mathrm{CMs}$ are applied at this point to control this reversible stage of DN [41]. Asparagus racemosus (lu-sun), Radix Astragali (huang-qi), Rosa laevigata (jin-ying-zi), and Piper auritum ( $h u$-jiao) were reported to enhance the activities of superoxide dismutase (SOD) and glutathione peroxidase (GSH-Px), leading to attenuation of the oxidative stress [5, 42-44].

\section{CMs intervention in the incipient stage of experimental DN}

The development of micro albuminuria was reported as an indicator of the incipient stage of $\mathrm{DN}$, arising from endothelial dysfunction [38, 45]. Renal hypertrophy and hyperfiltration induced functional and structural alterations, resulting in micro albuminuria and hypertension, leading to glomerulus sclerosis, and progressing to incipient DN. Cornus officinalis (shan-zhu-yu), Abelmoschus manihot (huang-shu-kui), Schisandrae chinensis (wu-wei$z i$ ), and Paeonia lactiflora (shao-yao) were reported to exhibit anti-micro albuminuria effects, thereby slowing down DN progression [19, 21, 46, 47]. 


\section{CMs intervention in the overt and end-stage renal disease (ESRD) stages of experimental DN}

After the incipient stage of DN and under hyperglycemic conditions, mesangial nodules and tubule interstitial fibrosis develop, leading to proteinuria and nephrotic syndrome, and eventually to the overt stage of $\mathrm{DN}$, which is characterized by persistent proteinuria [6]. Without effective control, patients in this stage will deteriorate to ESRD with uremia. As the kidney disease progresses, physical changes in the kidneys often lead to increased blood pressure and cardiovascular disease. In this stage, angiotensin-converting enzyme (ACE) inhibition is the conventional intervention [48]. The goal of treatment is to prevent the progression from micro albuminuria to macro albuminuria, and multiple and more intensive strategies are strongly advised. Avosentan was reported to reduce albuminuria in patients with type $2 \mathrm{DM}$ and overt nephropathy by inhibiting ACE and blocking angiotensin receptors, but can also induce significant fluid overload and congestive heart failure [49]. Averrhoa carambola L. (yang-tao), Salvia miltiorrhiza (dan-shen), and Picrorrhiza Rhizoma (hu-huang-lian) can ameliorate DN symptoms safely [50-52]. Representative CMs and their related mechanisms are summarized in Table 1.

Besides targeting the specific molecules involved in DN pathogenesis to exert anti-hyperglycemic and nephroprotective effects, CM has unique characteristics in DN management. In CM, DN is not only a kidney disease, but also an embodiment of the systemic disease in the kidney, which is in accordance with the latest findings for DN pathogenesis $[7,8,38]$. The pathogenesis of DN may be closely related to the dysfunction or impairment of other organs, and therefore treatments for diseases in other organs may be helpful for the amelioration of DN, especially in the overt and ESRD stages. The normal functioning of the human body relies on the coordination of yinand yang, and the five zang organs (wuzang), i.e., the liver (gan), heart (xin), spleen (pi), lung (fei), and kidney (shen), are respectively related to wood (mu), fire (huo), earth (tu), metal (jin), and water (shui) and connected under the laws of inter promotion and interaction (Fig. 3) [53]. Once a significant imbalance occurs, certain symptoms of the kidneys inevitably and predictably arise.

Under hyperglycemic conditions, the oxidative stress and inflammation affect the blood circulatory system, consequently leading to the dysfunction of multiple organs. Cardiovascular disease causes even more deaths than ESRD in patients with DN [38]. The degree of pulmonary function impairment was found to be positively associated with the stage of DN progression [7]. Besides, liver X receptor (LXR) agonists, which are commonly used to treat hyperlipidemia and non-alcoholic fatty liver disease, were shown to ameliorate $\mathrm{DN}$ by inhibiting the expressions of osteopontin and other inflammatory mediators in the kidney cortex [8]. Moreover, during DN pathogenesis, glomerular hypertrophy was found to be associated with hyperinsulinemia [54], and has been proposed as a novel therapeutic target for DN [55]. As a systematic micro vascular thrombosis combined with metabolic disorders, DN influences the whole internal environment, and its pathogenesis may be closely related to the dysfunction of other organs.

From this perspective, CM as a therapeutic approach targeting multiple organs is preferred to improve the overall health of DN patients. Experimentally, grapevine (Vitis labrusca L.) leaves exhibited hepatoprotective, cardioprotective, and renoprotective effects in Wistar rats [32]. Besides, extracts from S. miltiorrhiza exhibited a regulatory effect on the expression of LXR- $\alpha$ in hyperlipidemic rats [56]. Furthermore, Liuwei Dihuang Decoction exhibited a protective effect on early DN in STZ rats [57]. Additionally, a CM prescription, kangen-karyu, exhibited hepatoprotective/renoprotective activities through the inhibition of AGE formation and fibrosis-related protein expressions in type 2 diabetes [58]. Yamabe and colleagues systematically conducted a series of experiments to investigate the anti-diabetic effects of a CM prescription, hachimi-jio-ga, and reported findings for the whole prescription and its constituents as well as for the bioactive compound [59-64]. Other selected CM prescriptions for DN treatments and their respective molecular mechanisms are shown in Table 2. In particular, single herbs (e.g., Auricularia auricula, hei-mu-er) and CM prescriptions (e.g., Danggui Buxue Tang and Gui Qi Mixture) produced better beneficial effects than conventional anti-DN drugs by regulating blood lipid metabolism and lipoprotein lipase activity through the regulation of blood glucose based on their complex compound matrices [65-67]. The changes in blood glucose, triglyceride (TG), total cholesterol (TC), and high-density lipoprotein (HDL) were reversed by Gui Qi Mixture, but not by the ACE inhibitor benazepril in diabetic rats [68]. Similarly, the increases in fasting blood glucose (FBG), TG, and TC were attenuated, and the renal kidney/body weight $(\mathrm{K} / \mathrm{B})$ ratio, urinary albumin excretion (UAE), and creatinine clearance rate $(\mathrm{CCr})$ in STZ-induced diabetic rats were ameliorated after 8 weeks of treatment with Danggui Buxue Tang compared with benazepril [69]. Collectively, CMs may exert synergetic effects targeting multiple organs, and benefiting the whole internal milieu of DN patients.

At the ESRD stage, it is almost impossible to prevent the disease from becoming more severe, and dialysis may be the final resort for these patients. To provide a more cost-effective therapeutic approach, other potent remedies are urgently needed. In this regard, the combined 


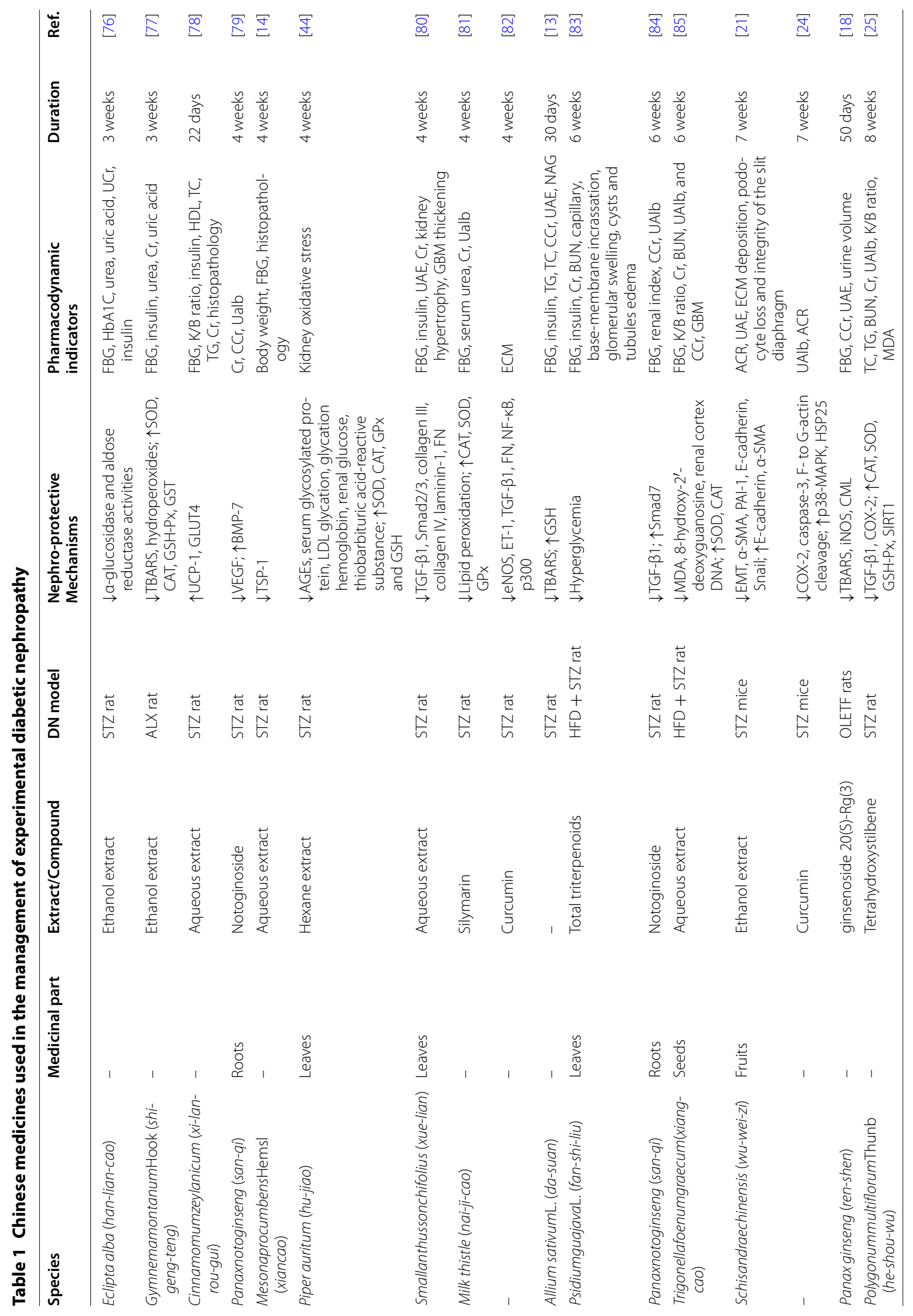




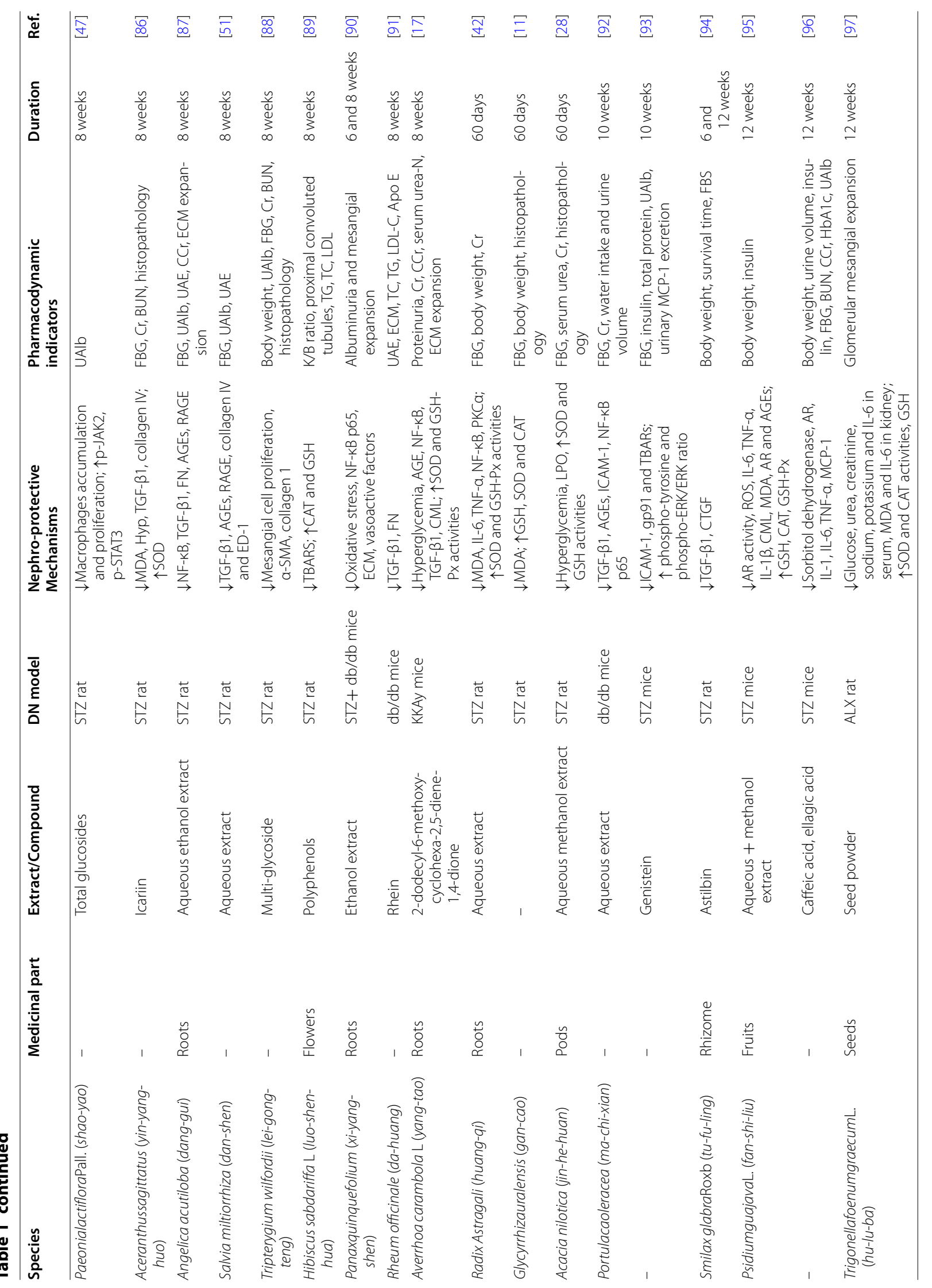




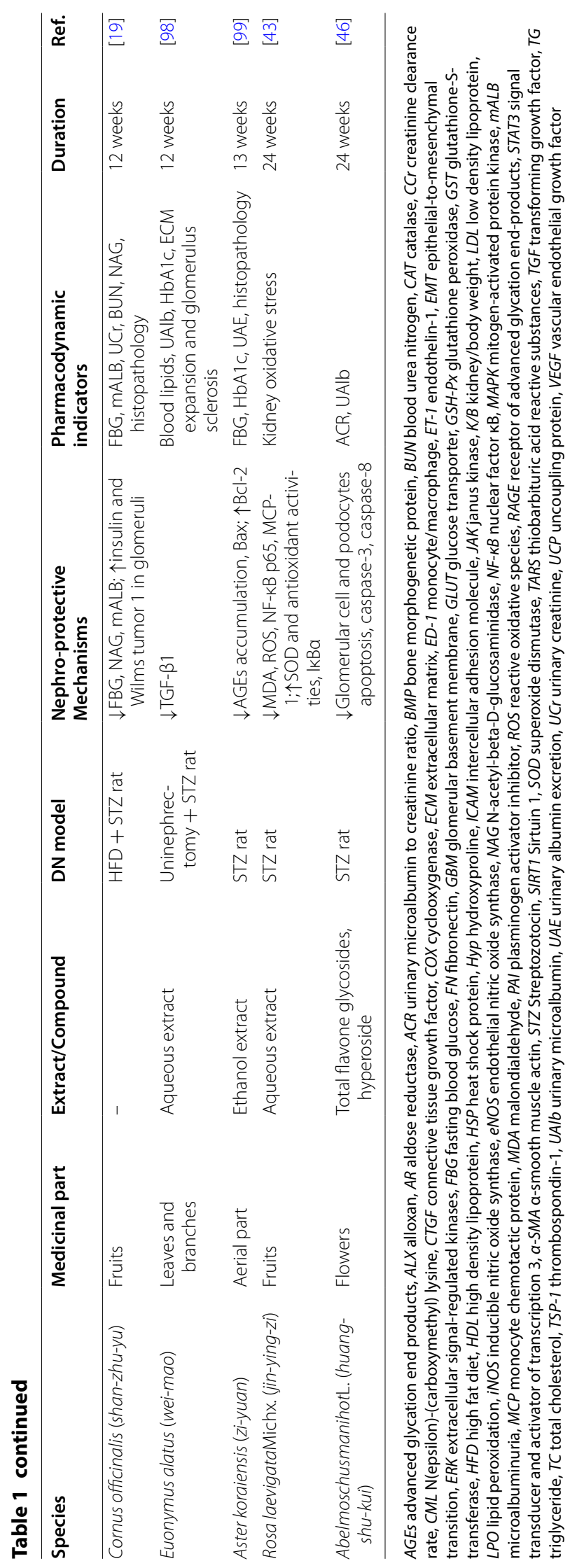




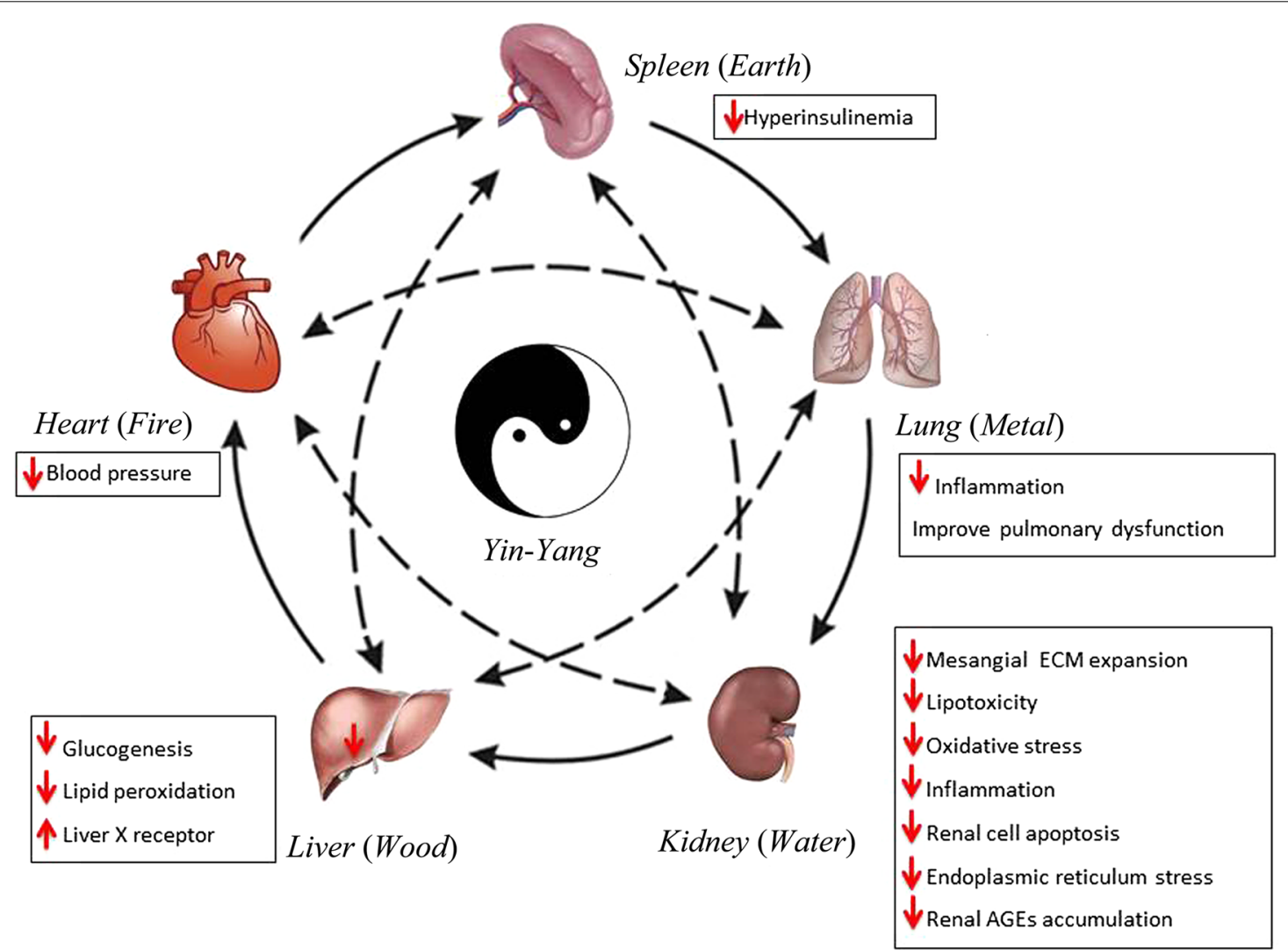

Fig. 3 Schematic diagram integrating the Chinese medicine (CM) view on the holistic therapy and modern pathogenesis concepts of diabetic nephropathy (DN). The core shows the holistic view of DN under CM theory, which is based on the Yin-Yang and Five Elements theories. The regular functioning of the human body relies on the coordination of Yin and Yang in a unity of opposites, and the liver, heart, spleen, lung, and kidneys are respectively related to wood, fire, earth, metal, and water [53]. In particular, the spleen in CM is a functional organ that governs transport and transformation in a close relationship with the stomach and pancreas [73-75]. This theory reflects the unification and integration together with the impact caused by the breakdown of the balance as a consequence of overacting and counteracting relationships, which is of practical significance in CM clinical practice. The peripheral annotations imply recent therapeutic strategies against DN specific to individual organs. The solid arrows denote interpromoting relationships. The dashed arrows indicate interacting/counteracting relationships

use of herbs and drugs, and the development of new therapies are receiving increasing attention.

Modern drugs specifically aim to target disease-related molecules through definite pathways, whereas CM aims to exert synergetic effects and benefit the whole internal milieu of patients, leading to the possibility that the combined use of CMs and modern drugs may exert better therapeutic effects on diseases, especially for chronic and comprehensive DN. Currently, the combined use of herbs and drugs in the treatment of DN has been wellinvestigated. For example, the CM prescription tangshenling was combined with telmisartan to treat 80 patients with $\mathrm{DN}$, and exhibited a better effect than telmisartan treatment alone [70]. Basic research corroborated that the tangshenling mixture had a synergetic effect with benazepril through a different signaling pathway, which involved down regulation of atrial natriuretic factor
(ANF) in plasma and glucose transporter 1 (GLUT1) in the kidney when treating DN [71]. Herbs may reduce the permeability of the drug into the intestinal tract, and may also affect its metabolism in the liver and cause hypoglycemia. Huang Kui capsule reduced the absorption of glibenclamide and accelerated its metabolism. This herb-drug interaction deserves further research on the herb-drug pharmacokinetic interaction to enhance the therapeutic effects and avoid side effects.

\section{Limitations of this review}

In many studies included in this review, the bioactivities of the CMs responsible for the anti-DN effects and their molecular targets were not identified. Phytochemical and molecular biological studies are needed to identify the bioactive constituents and to elucidate the underlying mechanisms. Moreover, this review only focused on 
Table 2 Experimental studies on selected CM prescriptions in diabetes nephropathy management

\begin{tabular}{|c|c|c|c|c|c|c|}
\hline CM preparations & DN model & $\begin{array}{l}\text { Nephro-protective } \\
\text { mechanisms }\end{array}$ & $\begin{array}{l}\text { Pharmacodynamic } \\
\text { indicators }\end{array}$ & Dosage & Duration & Ref. \\
\hline Xiao-chai-hu-tang & STZ rat & $\begin{array}{l}\downarrow \text { TGF- } \beta 1, \text { FN, and collagen } \\
\text { IV, } \uparrow \text { BMP-7, SOD }\end{array}$ & $\begin{array}{l}\text { FBG, BUN, SCr, renal hyper- } \\
\text { trophy }\end{array}$ & 200 mg/kg b.w & 4 weeks & {$[100]$} \\
\hline LiuweiDihuang Decoction & STZ rat & $\begin{array}{l}\downarrow M D A, \text { iNOS, tNOS, cNOS, } \\
\text { ET-1, ET(A), } \uparrow N O, \text { MMP-2, } \\
\text { MMP-9, GSH-Px, SOD }\end{array}$ & FBG, plasma insulin level & 5,10, or $15 \mathrm{~g} / \mathrm{kg}$ b.w & 4 weeks & {$[57]$} \\
\hline $\begin{array}{l}\text { Tangshenling mixture plus } \\
\text { benazepril }\end{array}$ & STZ rat & $\downarrow A N F$, GLUT1 & UAE, CCr, K/B ratio & $5 \mathrm{~g} / \mathrm{kg} \mathrm{b.w}$ & 6 weeks & {$[71]$} \\
\hline DangguiBuxue Tang & STZ rat & $\downarrow T G F-\beta 1$ & $\begin{array}{l}\text { K/B ratio, UAE, } \beta(2)-M G \\
\text { concentrations, } C C r, F B G, \\
\text { TC, TG }\end{array}$ & - & 8 weeks & {$[69]$} \\
\hline $\begin{array}{l}\text { Dang-gui and Huang-qi } \\
\text { mixture }\end{array}$ & STZ rat & $\downarrow T G F-\beta 1$, Ang $\|$ & $\begin{array}{l}\mathrm{FBG}, \mathrm{TG}, \mathrm{CHO}, \mathrm{HDL}, \mathrm{SCr}, \mathrm{CCr} \\
\text { BUN, } \beta(2)-\mathrm{MG}, \mathrm{K} / \mathrm{B} \text { ratio, GA }\end{array}$ & - & 8 weeks & {$[68]$} \\
\hline Tangshenning Recipe & STZ rat & $\begin{array}{l}\downarrow \text { TXB(2), TXB(2)/6-keto-PGF1 } \\
\text { a, CGRP, MDA; } \uparrow E T, \text { SOD, } \\
\text { GSH }\end{array}$ & - & $35 \mathrm{~g} / \mathrm{kg}$ b.w & 8 weeks & {$[101]$} \\
\hline Shenbao Recipe & STZ rat & $\downarrow C T G F, \uparrow M M P-9$ & UAlb, FBG, TC, SCr & $13 \mathrm{~g} / \mathrm{kg}$ b.w & 8 weeks & {$[102]$} \\
\hline Wu-ling-san & STZ rat & $\begin{array}{l}\downarrow N F-k B, T G F-\beta 1, F N, \text { AGEs, } \\
\quad \text { mitochondrial TBARS, CML }\end{array}$ & $\begin{array}{l}\text { UAE, UAlb, CCr, mesangial } \\
\text { matrix expansion }\end{array}$ & $2.5 \mathrm{~g} / \mathrm{kg} \mathrm{b.w}$ & 10 weeks & {$[103]$} \\
\hline Zhen-wu-tang & STZ rat & $\downarrow$ Ang II, $\uparrow$ nephrin, podocin & $\begin{array}{l}\text { Body weight, polyurea, UAE, } \\
\text { SCr, BUN }\end{array}$ & 320 mg/kg b.w. & 12 weeks & {$[72]$} \\
\hline $\begin{array}{l}\text { FufangXueshuantong } \\
\text { Capsule }\end{array}$ & $\begin{array}{l}\mathrm{HFD}+\mathrm{STZ} \\
\quad \text { rat }\end{array}$ & $\uparrow G S H-p x$, SOD & $\begin{array}{l}\text { UAE, CCr, masengial matrix } \\
\text { expansion }\end{array}$ & $\begin{array}{l}450,900 \text {, or } 1800 \text { mg/ } \\
\text { kg b.w }\end{array}$ & 12 weeks & [104] \\
\hline Hachimi-jio-gan & STZ rat & $\downarrow$ AGEs, sorbitol & $\begin{array}{l}\text { FBG, UAE, CCr, serum } \\
\text { glycosylated protein, BUN, } \\
\text { serum albumin level, TG, TC }\end{array}$ & 50,100, or 200 mg/kg b.w & 15 weeks & {$[59]$} \\
\hline Kangen-karyu & STZ mouse & $\downarrow A G E s, T G F-\beta 1$, collagen IV & FBG, BUN & 100,200 mg/kg b.w & 18 weeks & {$[58]$} \\
\hline Hachimi-jio-gan & OLETF rats & $\begin{array}{l}\downarrow N F-k B, T G F-\beta 1, F N, \text { iNOS, } \\
\text { cyclooxygenase- } 2, \text { AGEs, } \\
\text { TBARS }\end{array}$ & UAE, CCr, FBG & 50,100 , or 200 mg/kg b.w & 32 weeks & {$[61]$} \\
\hline $\begin{array}{l}\text { Yiqiyangyinhuayutongluo } \\
\text { recipe }\end{array}$ & $\begin{array}{l}\mathrm{HFD}+\mathrm{STZ} \\
\text { rat }\end{array}$ & $\uparrow$ Nephrin & FBG, UAE, 24 h U-nephrin & $0.8 \mathrm{~g} / \mathrm{kg}$ b.w & 32 weeks & {$[105]$} \\
\hline
\end{tabular}

AGEs advanced glycation end products, $A N F$ atrial natriuretic factor, Ang II angiotensin II, BMP bone morphogenetic protein, $B U N$ blood urea nitrogen, $C C r$ creatinine clearance rate, $C H O$ cholesterol, $C M L$ N(epsilon)-(carboxymethyl)lysine, CGRP calcitonin gene-related peptide, CTGF connective tissue growth factor, ET endothelin FBG fasting blood glucose, GA glomerular area, GLUT glucose transporter, TGF transforming growth factor, FN fibronectin, GSH-PX glutathione peroxidase, HDL high density lipoprotein, HFD high fat diet, $K / B$ kidney/body weight, NF-KB nuclear factor $K B, N O$ nitric oxide, $C N O S$ constitutive nitric oxide synthase, eNOS endothelial nitric oxide synthase, iNOS inducible nitric oxide synthase, $n N O S$ constitutive nitric oxide synthase, $t N O S$ total nitric oxide synthase, MDA malondialdehyde, $M M P$ matrix metalloproteinase, $\beta$ (2)-MG Urine $\beta$ (2)-microglobin, OLETF otsuka long-Evans Tokushima Fatty, PGF prostaglandin F, SCr serum creatinine clearance rate, STZ streptozotocin, SOD superoxide dismutase, TGF transforming growth factor, TG triglyceride, TC total cholesterol, TARS thiobarbituric acid reactive substances, TXB(2) thromboxane $\mathrm{B}$ 2, UAE urinary albumin excretion rate, UAlb urinary microalbumin

studies using in vitro or in vivo DN models. Results from clinical trials investigating the use of CMs for the treatment of DN are needed to confirm the therapeutic effects of CMs in the future.

\section{Conclusion}

CMs provides an alternative for DN management in all stages of experimental DN models, especially in the early and incipient stages of DN, and the synergistic administration of CM herbs with conventional drugs exhibited better efficacy than drugs alone in $\mathrm{DN}$ treatment.

\section{Abbreviations}

ANF: atrial natriuretic factor; AGEs: advanced glycation end products; Ang II: angiotensin II; ALX: alloxan; AR: aldose reductase; ACE: angiotensin-converting enzyme; ARB: angiotensin receptor blocker; ACR: urinary microalbumin to creatinine ratio; BUN: blood urea nitrogen; BMP: bone morphogenetic protein; CAT: catalase; CCr: creatinine clearance rate; CGRP: calcitonin generelated peptide; $\mathrm{CHO}$ : cholesterol; $\mathrm{CTGF}$ : connective tissue growth factor; CML: n(epsilon)-(carboxymethyl)lysine; DM: diabetes mellitus; DN: diabetic nephropathy; ER: endoplasmic reticulum; ET-1: endothelin-1; ESRD: end-stage renal disease; EMT: epithelial-to-mesenchymal transition; ECM: extracelIular matrix; EMMPRIN: extracellular matrix metalloproteinase inducer; ERK: extracellular signal-regulated kinases; ED-1: monocyte/macrophage; FBG: fasting blood glucose; FN: fibronectin; GA: glomerular area; GFR: glomerular filtration rate; GMCs: glomerular mesangial cells; GBM: glomerular basement membrane; GSH-Px: glutathione peroxidase; GST: glutathione-S-transferase; GLUT: glucose transporter; HDL: high density lipoprotein; HFD: high fat diet; Hyp: hydroxyproline; iNOS: inducible nitric oxide synthase; ICAM: intercellular adhesion molecule; IGF: insulin-like growth factor; K/B: kidney/body weight; LPO: lipid peroxidation; LPL: lipoprotein lipase; LXR: liver X receptor; LDL: low density lipoprotein; NAG: n-acetyl-beta-D-glucosaminidase; eNOS: endothelial nitric oxide synthase; nNOS: constitutive nitric oxide synthase; tNOS: total nitric oxide synthase; MAPK: mitogen-Activated Protein Kinase; mALB: 
microalbuminuria; MDA: malondialdehyde; MMP: matrix metalloproteinase MCP: monocyte chemotactic protein; OLETF: otsuka Long-Evans Tokushima Fatty; PPAR: peroxisome proliferator-activated receptor; PAl: plasminogen activator inhibitor; PK1: protein kinase 1; PGF: prostaglandin F; ROS: reactive oxidative species; RAGE: receptor of advanced glycation end-products; SGK serum and glucocorticoid induced protein kinase; STZ: streptozotocin; SOD: superoxide dismutase; a-SMA: a-smooth muscle actin; SCr: serum creatinine clearance rate; TGF: transforming growth factor; CM: chinese medicine; TARS: thiobarbituric acid reactive substances; TIMP: tissue inhibitor of metalloproteinase; TG: triglyceride; TC: total cholesterol; TSP-1: thrombospondin-1; TXB(2): thromboxane B 2; UCr: urinary creatinine; $\beta$ (2)-MG: urine $\beta$ (2)-microglobin; UCP: uncoupling protein; UAlb: urinary microalbumin; UPR: unfolded protein response; UAE: urinary albumin excretion; VEGF: vascular endothelial growth factor.

\section{Authors' contributions}

YBZ and SCWT designed and conceived the study. JYL, XXC, SCWS, YBF, and KFL select and analyzed the data. JYL, XXC, SCWS, KFL, and YBF wrote the manuscript. YBZ and SCWT revised the manuscript. All authors agree to be responsible to all aspects of the work to ensure that no questions concerning the accuracy or integrity of the work remain unsolved. All authors read and approved the final manuscript.

\section{Author details \\ ${ }^{1}$ School of Chinese Medicine, Li Ka Shing Faculty of Medicine, The University of Hong Kong, 10 Sassoon Road, Hong Kong, People's Republic of China. 2 Department of Medicine, Li Ka Shing Faculty of Medicine, The University of Hong Kong, 10 Sassoon Road, Hong Kong, People's Republic of China. ${ }^{3}$ Obstetrics and Gynaecology, Li Ka Shing Faculty of Medicine, The University of Hong Kong, 10 Sassoon Road, Hong Kong, People's Republic of China.}

\section{Acknowledgements}

This study was supported by grants from Seed Funding Programme for Basic Research from HKU (Project No. 201111159043); the Innovation and Technology Support Programme (Project code: ITS/313/11); and the Government of Hong Kong Special Administrative Region. The funders had no role in the design, analysis or writing of this article.

\section{Competing interests}

The authors declare that they have no competing interests.

Received: 29 November 2014 Accepted: 26 January 2016

Published online: 24 February 2016

\section{References}

1. Gross JL, de Azevedo MJ, Silveiro SP, Canani LH, Caramori ML, Zelmanovitz T. Diabetic nephropathy: diagnosis, prevention, and treatment. Diabetes Care. 2005;28:164-76.

2. Liu JY, Chen XX, Tang SCW, Lao LX, Sze SCW, Lee KF, Zhang KYB. Edible plants from traditional Chinese medicine is a promising alternative for the management of diabetic nephropathy. J Funct Foods. 2015;14:12-22.

3. Tripathi YB, Yadav D. Diabetic nephropathy: causes and managements Recent Pat Endocr Metab Immune Drug Discov. 2013;7:57-64.

4. Forbes JM, Fukami K, Cooper ME. Diabetic nephropathy: where hemodynamics meets metabolism. Exp Clin Endocr Diab. 2007;115:69-84.

5. Somania R, Singhai AK, Shivgunde P, Jain D. Asparagus racemosus Willd (Liliaceae) ameliorates early diabetic nephropathy in STZ induced diabetic rats. Indian J Exp Biol. 2012;50:469-75.

6. Zelmanovitz T, Gerchman F, Balthazar AP, Thomazelli FC, Matos JD, Canani LH. Diabetic nephropathy. Diabetol Metab Syndr. 2009;1:10.

7. Shafiee G, Khamseh ME, Rezaei N, Aghili R, Malek M. Alteration of pulmonary function in diabetic nephropathy. J Diabetes Metab Disord. 2013;12:15.

8. Tachibana H, Ogawa D, Matsushita Y, Bruemmer D, Wada J, Teshigawara S, Eguchi J, Sato-Horiguchi C, Uchida HA, Shikata K, Makino H. Activation of liver $X$ receptor inhibits osteopontin and ameliorates diabetic nephropathy. J Am Soc Nephrol. 2012;23:1835-46.
9. Foley RN, Culleton BF, Parfrey PS, Harnett JD, Kent GM, Murray DC, Barre PE. Cardiac disease in diabetic end-stage renal disease. Diabetologia. 1997:40:1307-12.

10. Gilbert RE, Connelly K, Kelly DJ, Pollock CA, Krum H. Heart failure and nephropathy: catastrophic and interrelated complications of diabetes. Clin J Am Soc Nephrol. 2006;1:193-208.

11. Kataya HH, Hamza AA, Ramadan GA, Khasawneh MA. Effect of licorice extract on the complications of diabetes nephropathy in rats. Drug Cheml Toxicol. 2011;34:101-8.

12. Sadiq S, Nagi AH, Shahzad M, Zia A. The reno-protective effect of aqueous extract of Carum carvi (black zeera) seeds in streptozotocin induced diabetic nephropathy in rodents. Saudi J Kidney Dis Transpl. 2010;21:1058-65.

13. Mariee AD, Abd-Allah GM, El-Yamany MF. Renal oxidative stress and nitric oxide production in streptozotocin-induced diabetic nephropathy in rats: the possible modulatory effects of garlic (Allium sativum L.) Biotechnol Appl Biochem. 2009:52:227-32.

14. Yang M, Xu ZP, Xu CJ, Meng J, Ding GQ, Zhang XM, Weng Y. Renal protective activity of Hsian-tsao extracts in diabetic rats. Biomed Environ Sci. 2008;21:222-7.

15. Orsolic N, Sirovina D, Koncic MZ, Lackovic G, Gregorovic G. Effect of Croatian propolis on diabetic nephropathy and liver toxicity in mice. BMC Complement Altern Med. 2012;12:117.

16. Yan SJ, Wang L, Li Z, Zhu DN, Guo SC, Xin WF, Yang YF, Cong X, Ma T, Shen PP, Sheng J, Zhang WS. Inhibition of advanced glycation end product formation by Pu-erh tea ameliorates progression of experimental diabetic nephropathy. J Agr Food Chem. 2012;60:4102-10.

17. Zheng N, Lin X, Wen Q, Kintoko, Zhang S, Xu X, Huang J, Huang R. Effect of 2-dodecyl-6-methoxycyclohexa-2,5-diene-1,4-dione, isolated from Averrhoa carambola L. (Oxalidaceae) roots, on advanced glycation endproduct-mediated renal injury in type 2 diabetic KKAy mice. Toxicol Lett. 2013;219:77-84.

18. Kang KS, Yamabe N, Kim HY, Park JH, Yokozawa T. Effects of heat-processed ginseng and its active component ginsenoside 20(S)-Rg3 on the progression of renal damage and dysfunction in type 2 diabetic Otsuka Long-Evans Tokushima Fatty rats. Biol Pharm Bull. 2010;33:1077-81.

19. Liu H, Xu H, Shen C, Wu C. Effect of the best compatibility of components in Corni Fructus on WT1 expression in glomerular podocytes of type 2 diabetic rats with early nephropathy. Am J Chin Med. 2012:40:537-49.

20. Tang D, He B, Zheng ZG, Wang RS, Gu F, Duan TT, Cheng HQ, Zhu Q. Inhibitory effects of two major isoflavonoids in Radix Astragali on high glucose-induced mesangial cells proliferation and AGEs-induced endothelial cells apoptosis. Planta Med. 2011;77:729-32.

21. Zhang M, Liu M, Xiong M, Gong J, Tan X. Schisandra chinensis fruit extract attenuates albuminuria and protects podocyte integrity in a mouse model of streptozotocin-induced diabetic nephropathy. J Ethnopharmacol. 2012;141:111-8.

22. Yu DQ, Gao Y, Liu XH. Effects of Rhein on the hypertrophy of renal proximal tubular epithelial cells induced by high glucose and angiotensin II in rats. Zhong Yao Cai. 2010;33:570-4.

23. Xie Y, Wang Q, Liu J, Xie J, Xue K, Tang Q. Dracorhodin perchlorate inhibit high glucose induce serum and glucocorticoid induced protein kinase 1 and fibronectin expression in human mesangial cells. Zhongguo Zhong Yao Za Zhi. 2010;35:1996-2000.

24. Ma J, Phillips L, Wang Y, Dai T, LaPage J, Natarajan R, Adler SG. Curcumin activates the p38MPAK-HSP25 pathway in vitro but fails to attenuate diabetic nephropathy in DBA2 J mice despite urinary clearance documented by HPLC. BMC Complement Altern Med. 2010;10:67.

25. Li C, Cai F, Yang Y, Zhao X, Wang C, Li J, Jia Y, Tang J, Liu Q. Tetrahydroxystilbene glucoside ameliorates diabetic nephropathy in rats: involvement of SIRT1 and TGF-beta1 pathway. Eur J Pharmacol. 2010;649:382-9.

26. Lee MJ, Rao YK, Chen K, Lee YC, Chung YS, Tzeng YM. Andrographolide and 14-deoxy-11,12-didehydroandrographolide from Andrographis paniculata attenuate high glucose-induced fibrosis and apoptosis in murine renal mesangeal cell lines. J Ethnopharmacol. 2010;132:497-505.

27. Li X, Xiao Y, Gao H, Li B, Xu L, Cheng M, Jiang B, Ma Y. Grape seed proanthocyanidins ameliorate diabetic nephropathy via modulation of levels of AGE, RAGE and CTGF. Nephron Exp Nephrol. 2009;111:e31-41. 
28. Omara EA, Nada SA, Farrag AR, SharafWM, El-Toumy SA. Therapeutic effect of Acacia nilotica pods extract on streptozotocin induced diabetic nephropathy in rat. Phytomedicine. 2012;19:1059-67.

29. Sefi M, Fetoui H, Soudani N, Chtourou Y, Makni M, Zeghal N. Artemisia campestris leaf extract alleviates early diabetic nephropathy in rats by inhibiting protein oxidation and nitric oxide end products. Pathol Res Pract. 2012;208:157-62

30. Wang K, Wu YG, Su J, Zhang JJ, Zhang P, Qi XM. Total glucosides of paeony regulates JAK2/STAT3 activation and macrophage proliferation in diabetic rat kidneys. Am J Chinese Med. 2012;40:521-36.

31. Wang BL, Hu JP, Tan W, Sheng L, Chen H, Li Y. Simultaneous quantification of four active schisandra lignans from a traditional Chinese medicine Schisandra chinensis (Wuweizi) in rat plasma using liquid chromatography/mass spectrometry. J Chromatogr B. 2008;865:114-20.

32. Oliboni LS, Dani C, Funchal C, Henriques JA, Salvador M. Hepatoprotective, cardioprotective, and renal-protective effects of organic and conventional grapevine leaf extracts on Wistar rat tissues. Anais da Academia Brasileira de Ciencias. 2011:83:1403-11.

33. Zhang Q, Xiao X, Li M, Li W, Yu M, Zhang H, Sun X, Mao L, Xiang H. Attenuating effect of Fufang Xueshuantong Capsule on kidney function in diabetic nephropathy model. J Nat Med. 2013;67:86-97.

34. Wen $X$, Zeng $Y$, Liu L, Zhang $H$, Xu W, Li N, Jia X. Zhenging recipe alleviates diabetic nephropathy in experimental type 2 diabetic rats through suppression of SREBP-1c. J Ethnopharmacol. 2012;142:144-50.

35. Ke HL, Zhang YW, Zhou BF, Zhen RT. Effects of Danggui Buxue Tang, a traditional Chinese herbal decoction, on high glucose-induced proliferation and expression of extracellular matrix proteins in glomerular mesangial cells. Nat Prod Res. 2012;26:1022-6.

36. Yiu WH, Wong DW, Chan LY, Leung JC, Chan KW, Lan HY, Lai KN, Tang SC. Tissue kallikrein mediates pro-inflammatory pathways and activation of protease-activated receptor-4 in proximal tubular epithelial cells. PLOS ONE. 2014;9:e88894.

37. Lin M, Yiu WH, Wu HJ, Chan LY, Leung JC, Au WS, Chan KW, Lai KN, Tang SC. Toll-like receptor 4 promotes tubular inflammation in diabetic nephropathy. J Am Soc Nephrol. 2012;23:86-102.

38. Singh DK, Winocour P, Farrington K. Oxidative stress in early diabetic nephropathy: fueling the fire. Nat Rev Endocrinol. 2011;7:176-84.

39. Chung SSM, Ho ECM, Lam KSL, Chung SK. Contribution of polyol pathway to diabetes-induced oxidative stress. J Am Soc Nephrol. 2003;14:S233-6.

40. Wada J, Makino H. Inflammation and the pathogenesis of diabetic nephropathy. Clin Sci. 2013;124:139-52.

41. Fioretto P, Barzon I, Mauer M. Is diabetic nephropathy reversible? Diabetes Res Clin Pr. 2014;104:323-8.

42. Gao Y, Zhang RR, Li JH, Ren M, Ren ZX, Shi JH, Pan QZ, Ren SP. Radix Astragali lowers kidney oxidative stress in diabetic rats treated with insulin. Endocrine. 2012;42:592-8.

43. Zhou Y, Liao Q, Luo Y, Qing Z, Zhang Q, He G. Renal protective effect of Rosa laevigata Michx by the inhibition of oxidative stress in streptozotocin-induced diabetic rats. Mol Med Rep. 2012;5:1548-54.

44. Perez Gutierrez RM, Flores Cotera LB, Gonzalez AM. Evaluation of the antioxidant and anti-glication effects of the hexane extract from Piper auritum leaves in vitro and beneficial activity on oxidative stress and advanced glycation end-product-mediated renal injury in streptozotocin-treated diabetic rats. Molecules. 2012;17:11897-919.

45. Yaqoob M, Patrick AW, McClelland P, Stevenson A, Mason H, White MC, Bell GM. Relationship between markers of endothelial dysfunction, oxidant injury and tubular damage in patients with insulin-dependent diabetes mellitus. Clin Sci. 1993;85:557-62.

46. Zhou L, An XF, Teng SC, Liu JS, Shang WB, Zhang AH, Yuan YG, Yu JY. Pretreatment with the total flavone glycosides of Flos Abelmoschus manihot and hyperoside prevents glomerular podocyte apoptosis in streptozotocin-induced diabetic nephropathy. J Med Food. 2012;15:461-8.

47. Wang K, Wu YG, Su J, Zhang JJ, Zhang P, Qi XM. Total glucosides of paeony regulates JAK2/STAT3 activation and macrophage proliferation in diabetic rat kidneys. Am J Chin Med. 2012;40:521-36.

48. Ruggenenti P, Perna A, Remuzzi G, Gruppo Italiano di Studi Epidemiologici in N. ACE inhibitors to prevent end-stage renal disease: when to start and why possibly never to stop: a post hoc analysis of the
REIN trial results. ramipril efficacy in nephropathy. J Am Soc Nephrol. 2001;12:2832-7.

49. Mann JF, Green D, Jamerson K, Ruilope LM, Kuranoff SJ, Littke T, Viberti G, Group AS. Avosentan for overt diabetic nephropathy. J Am Soc Nephrol. 2010;21:527-35.

50. Zheng N, Lin X, Wen QW, Kintoko, Zhang SJ, Huang JC, Xu XH, Huang RB. Effect of 2-dodecyl-6-methoxycyclohexa-2,5-diene-1,4-dione, isolated from Averrhoa carambola L. (Oxalidaceae) roots, on advanced glycation end-product-mediated renal injury in type 2 diabetic KKAy mice. Toxicol Lett. 2013;219:77-84.

51. Lee SH, Kim YS, Lee SJ, Lee BC. The protective effect of Salvia miltiorrhiza in an animal model of early experimentally induced diabetic nephropathy. J Ethnopharmacol. 2011;137:1409-14.

52. Lee HS, Ku SK. Effect of Picrorrhiza Rhizoma extracts on early diabetic nephropathy in streptozotocin-induced diabetic rats. J Med Food. 2008;11:294-301.

53. Zhu B, Wang H. Basic theories of traditional Chinese medicine. Singing Dragon. 2011; p. 21-35.

54. Cusumano AM, Bodkin NL, Hansen BC, lotti R, Owens J, Klotman PE, Kopp JB. Glomerular hypertrophy is associated with hyperinsulinemia and precedes overt diabetes in aging rhesus monkeys. Am J Kidney Dis. 2002:40:1075-85.

55. Ohtomo S. The development of novel therapeutic targets for diabetic nephropathy: hyperinsulinemia, HIF-1, and megsin. Jpn J Vet Res. 2010;58:41.

56. Ji W, Gong BQ. Hypolipidemic activity and mechanism of purified herbal extract of Salvia miltiorrhiza in hyperlipidemic rats. J Ethnopharmacol. 2008;119:291-8.

57. He H, Yang X, Zeng X, Shi M, Yang J, Wu L, Li L. Protective effect of Liuwei Dihuang decoction on early diabetic nephropathy induced by streptozotocin via modulating ET-ROS axis and matrix metalloproteinase activity in rats. J Pharm Pharmacol. 2007;59:1297-305.

58. Okamoto T, Park CH, Noh JS, Toriizuka K, Sei Y, Park JC, Yokozawa T. Hepato-/reno-protective activity of Chinese prescription Kangenkaryu through inhibition of AGE formation and fibrosis-related protein expression in type 2 diabetes. J Pharm Pharmacol. 2011;63:952-9.

59. Yokozawa T, Yamabe N, Cho EJ, Nakagawa T, Oowada S. A study on the effects to diabetic nephropathy of Hachimi-jio-gan in rats. Nephron Exp Nephrol. 2004;97:e38-48.

60. Nakagawa T, Yokozawa T, Yamabe N, Rhyn DY, Goto H, Shimada Y, Shibahara N. Long-term treatment with Hachimi-jio-gan attenuates kidney damage in spontaneously diabetic WBN/Kob rats. J Pharm Pharmacol. 2005;57:1205-12.

61. Yamabe N, Yokozawa T. Activity of the Chinese prescription Hachimi-jiogan against renal damage in the Otsuka Long-Evans Tokushima fatty rat: a model of human type 2 diabetes mellitus. J Pharm Pharmacol. 2006;58:535-45

62. Yamabe N, Kang KS, Goto E, Tanaka T, Yokozawa T. Beneficial effect of Corni Fructus, a constituent of Hachimi-jio-gan, on advanced glycation end-product-mediated renal injury in streptozotocin-treated diabetic rats. Biol Pharm Bull. 2007;30:520-6.

63. Yamabe N, Yokozawa T. Protective effect of Hachimi-jio-gan against the development of pancreatic fibrosis and oxidative damage in Otsuka Long-Evans Tokushima Fatty rats. J Ethnopharmacol. 2007;113:91-9.

64. Yokozawa T, Yamabe N, Kim HY, Kang KS, Hur JM, Park CH, Tanaka T. Protective effects of morroniside isolated from Corni Fructus against renal damage in streptozotocin-induced diabetic rats. Biol Pharm Bull. 2008;31:1422-8

65. Chen G, Luo YC, Li BP, Li B, Guo Y, Li Y, Su W, Xiao ZL. Effect of polysaccharide from Auricularia auricula on blood lipid metabolism and lipoprotein lipase activity of ICR mice fed a cholesterol-enriched diet. J Food Sci. 2008;73:H103-8.

66. Yuan Z, He P, Cui J, Takeuchi H. Hypoglycemic effect of water-soluble polysaccharide from Auricularia auricula-judae Quel. on genetically diabetic KK-Ay mice. Biosci Biotech. Biochem. 1998;62:1898-903.

67. Xueyu Z, Youdi L, Fei H, Lili C, Mingde L. Pharmacological actions of hyphae body of Auricularia auricula (L. ex Hook) underw and its alcoholic extract. Zhongguo Zhong Yao Za Zhi. 1994;19:430-2.

68. Zhang $Y, X i e ~ D, C h e n ~ Y, Z$ hang $H$, Xia Z. Protective effect of Gui Qi mixture on the progression of diabetic nephropathy in rats. Exp Clin Endocrinol Diabetes. 2006;114:563-8. 
69. Zhang YW, Xie D, Xia B, Zhen RT, Liu IM, Cheng JT. Suppression of transforming growth factor-beta1 gene expression by Danggui buxue tang, a traditional Chinese herbal preparation, in retarding the progress of renal damage in streptozotocin-induced diabetic rats. Horm Metab Res. 2006;38:82-8.

70. Li JP, He XL, Li Q. Clinical study on treatment of early diabetic nephropathy by tangshenling combined with telmisartan. Zhongguo Zhong Xi Yi Jie He Za Zhi. 2006;26:415-8.

71. He XL, Li JP, Chen YP, Zhang ZG, Lin WQ, Chen JH. Effects of Tangshenling mixture and benazepril on rats with diabetic nephropathy and its mechanism. Zhong Xi Yi Jie He Xue Bao. 2006;4:43-7.

72. Cai Y, Chen J, Jiang J, Cao W, He L. Zhen-wu-tang, a blended traditional Chinese herbal medicine, ameliorates proteinuria and renal damage of streptozotocin-induced diabetic nephropathy in rats. J Ethnopharmacol. 2010;131:88-94.

73. Wu XN. Current concept of spleen-stomach theory and spleen deficiency syndrome in TCM. World J Gastroentero. 1998;4:2-6.

74. Liu YZ, Song YF, Lao SX, Deng TT, Wang JH. Ultramicrostructure research of gastric mucosa of gastric abscess patients and realization of the TCM theory of "spleen-mitochondria correlation" Zhong Hua Zhong Yi Yao Za Zhi. 2007;12:2439-2442.

75. Covington MB. Traditional Chinese medicine in the treatment of diabetes. Diabetes Spectrum. 2011;14:154-9.

76. Jaiswal N, Bhatia V, Srivastava SP, Srivastava AK, Tamrakar AK. Antidiabetic effect of Eclipta alba associated with the inhibition of alphaglucosidase and aldose reductase. Nat Prod Res. 2012;26:2363-7.

77. Ramkumar KM, Ponmanickam P, Velayuthaprabhu S, Archunan G, Rajaguru P. Protective effect of Gymnema montanum against renal damage in experimental diabetic rats. Food Chem Toxicol. 2009;47:2516-21.

78. Shen Y, Fukushima M, Ito Y, Muraki E, Hosono T, Seki T, Ariga T. Verification of the antidiabetic effects of cinnamon (Cinnamomum zeylanicum) using insulin-uncontrolled type 1 diabetic rats and cultured adipocytes. Biosci Biotech Bioch. 2010;74:2418-25.

79. Tu Q, Qin J, Dong H, Lu F, Guan W. Effects of Panax notoginoside on the expression of TGF-beta1 and Smad-7 in renal tissues of diabetic rats. J Huazhong U Sci-Med. 2011;31:190-3.

80. Honore SM, Cabrera WM, Genta SB, Sanchez SS. Protective effect of yacon leaves decoction against early nephropathy in experimental diabetic rats. Food Chem Toxicol. 2012;50:1704-15.

81. Vessal G, Akmali M, Najafi P, Moein MR, Sagheb MM. Silymarin and milk thistle extract may prevent the progression of diabetic nephropathy in streptozotocin-induced diabetic rats. Ren Fail. 2010;32:733-9.

82. Chiu J, Khan ZA, Farhangkhoee H, Chakrabarti S. Curcumin prevents diabetes-associated abnormalities in the kidneys by inhibiting p300 and nuclear factor-kappa B. Nutrition. 2009;25:964-72.

83. Kuang QT, Zhao JJ, Ye CL, Wang JR, Ye KH, Zhang XQ, Wang Y, Ye WC. Nephro-protective effects of total triterpenoids from Psidium guajava leaves on type 2 diabetic rats. Zhong Yao Cai. 2012;35:94-7.

84. Tu QN, Dong H, Lu FE. Effects of Panax notoginoside on the nephropathy in rats with type 1 diabetes mellitus. Chin J Integr Med. 2011;17:612-5.

85. Xue W, Lei J, Li X, Zhang R. Trigonella foenum graecum seed extract protects kidney function and morphology in diabetic rats via its antioxidant activity. Nutr Res. 2011;31:555-62.

86. Qi MY, Kai C, Liu HR, Su YH, Yu SQ. Protective effect of Icariin on the early stage of experimental diabetic nephropathy induced by streptozotocin via modulating transforming growth factor beta1 and type IV collagen expression in rats. J Ethnopharmacol. 2011;138:731-6.

87. Liu IM, Tzeng TF, Liou SS, Chang CJ. Angelica acutiloba root alleviates advanced glycation end-product-mediated renal injury in streptozotocin-diabetic rats. J Food Sci. 2011;76:H165-74.
88. Zhang H, Sun W, Wan Y, Che X, He F, Pu H, Dou C. Preventive effects of multi-glycoside of Tripterygium wilfordii on glomerular lesions in experimental diabetic nephropathy. Zhongguo Zhong Yao Za Zhi. 2010;35:1460-5

89. Lee WC, Wang CJ, Chen YH, Hsu JD, Cheng SY, Chen HC, Lee HJ. Polyphenol extracts from Hibiscus sabdariffa Linnaeus attenuate nephropathy in experimental type 1 diabetes. J Agr Food Chem. 2009;57:2206-10.

90. Sen S, Chen S, Feng B, Wu Y, Lui E, Chakrabarti S. Preventive effects of North American ginseng (Panax quinquefolium) on diabetic nephropathy. Phytomedicine. 2012;19:494-505.

91. Gao Q, Qin WS, Jia ZH, Zheng JM, Zeng CH, Li LS, Liu ZH. Rhein improves renal lesion and ameliorates dyslipidemia in $\mathrm{db} / \mathrm{db}$ mice with diabetic nephropathy. Planta Med. 2010;76:27-33.

92. Lee AS, Lee YJ, Lee SM, Yoon JJ, Kim JS, Kang DG, Lee HS. An aqueous extract of Portulaca oleracea ameliorates diabetic nephropathy through suppression of renal fibrosis and inflammation in diabetic $\mathrm{db} / \mathrm{db}$ mice. Am J Chinese Med. 2012:40:495-510.

93. Elmarakby AA, Ibrahim AS, Faulkner J, Mozaffari MS, Liou Gl, Abdelsayed $R$. Tyrosine kinase inhibitor, genistein, reduces renal inflammation and injury in streptozotocin-induced diabetic mice. Vasc Pharmacol. 2011;55:149-56.

94. Li GS, Jiang WL, Yue XD, Qu GW, Tian JW, Wu J, Fu FH. Effect of astilbin on experimental diabetic nephropathy in vivo and in vitro. Planta Med. 2009;75:1470-5

95. Lin CY, Yin MC. Renal protective effects of extracts from guava fruit (Psidium guajava L.) in diabetic mice. Plant Foods Hum Nutr. 2012;67:303-8.

96. Chao CY, Mong MC, Chan KC, Yin MC. Anti-glycative and anti-inflammatory effects of caffeic acid and ellagic acid in kidney of diabetic mice. Mol Nutr Food Res. 2010;54:388-95.

97. Sayed AA, Khalifa M. Abd el-Latif FF. Fenugreek attenuation of diabetic nephropathy in alloxan-diabetic rats: attenuation of diabetic nephropathy in rats. J Physiol Biochem. 2012;68:263-9.

98. Chang B, Jin C, Zhang W, Kong L, Yang JH, Lian FM, Li QF, Yu B, Liu WK, Yang $L L$, Zhao $P$, Zhen Z. Euonymus alatus in the treatment of diabetic nephropathy in rats. Am J Chinese Med. 2012;40:1177-87.

99. Sohn E, Kim J, Kim CS, Kim YS, Jang DS, Kim JS. Extract of the aerial parts of Aster koraiensis reduced development of diabetic nephropathy via anti-apoptosis of podocytes in streptozotocin-induced diabetic rats. Biochem Biophy Res Co. 2010;391:733-8.

100. Lin CC, Lin LT, Yen MH, Cheng JT, Hsing CH, Yeh CH. Renal protective effect of xiao-chai-hu-tang on diabetic nephropathy of type 1-diabetic mice. Evid Based Complement Alternat Med. 2012;2012:984024.

101. He LQ, Cao HX, Shen YJ. Effect and mechanism of Tangshenning Recipe on micro-albuminuria in rats with early diabetic nephropathy. Zhong Xi Yi Jie He Xue Bao. 2003;1:119-21.

102. Liu W, Wang J, Wang X, Yang Q, Wang D. Effects of shenbao recipe on expressions of CTGF and MMP-9 in diabetic nephropathy rats. Zhongguo Zhong Yao Za Zhi. 2010;35:1874-7.

103. Liu IM, Tzeng TF, Liou SS, Chang CJ. The amelioration of streptozotocin diabetes-induced renal damage by Wu-Ling-San (Hoelen Five Herb Formula), a traditional Chinese prescription. J Ethnopharmacol. 2009;124:211-8.

104. Fang D, Wan X, Deng W, Guan H, Ke W, Xiao H, Li Y. Fufang Xue Shuan Tong capsules inhibit renal oxidative stress markers and indices of nephropathy in diabetic rats. Exp Ther Med. 2012;4:871-6.

105. Li LL, Chen ZQ, Wang YH, Zhang JH, Yin ZW, Li LL, Zhang XY, Wang FL. Relationship between urinary nephrin and urinary albumin changes in diabetic rats and effects of Yiqiyangyinhuayutongluo Recipe. J Tradit Chin Med. 2012;32:278-82. 